\title{
Evidence base prioritisation of indoor comfort perceptions in Malaysian typical multi- storey hostels
}

\begin{abstract}
This study focuses on assessing the effects of the indoor climate in typical multi-storey hostels in Malaysia on student occupants through objective, subjective and evidence based prioritisation measurements. The objective measurements consisted of operative temperature; daylight ratio; luminance and indoor noise level. The subjective measurements were sampled from the student occupants' thermal, visual, acoustics and overall indoor comfort votes. The prioritisation measurement using Multiple Linear Regression and Friedman Tests assessed the relationship between physical indoor thermal, visual and acoustics conditions and students' overall indoor comfort perception vote. Findings suggest that subjective sensor ratings were significantly more reliable than objective measurements at predicting overall indoor comfort. Moreover, students living in hostel rooms with projected balconies voted that they were more satisfied with their indoor condition than the ones living in rooms without projected balconies. The results of this study also provide evidence that student occupants were more concerned with their rooms' thermal condition then followed by acoustics and finally visual conditions.
\end{abstract}

Keyword: Typical multi-storey hostels; Prioritisation of indoor comfort; Thermal comfort; Visual comfort; Acoustic comfort; Balcony; Questionnaire survey 